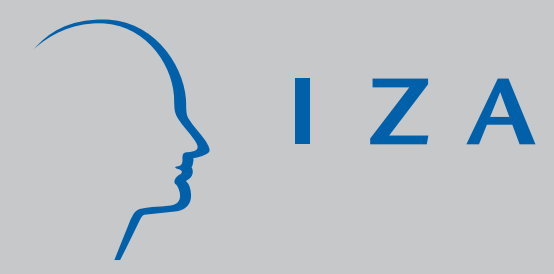

IZA DP No. 1380

Selection Policy and the Labour Market Outcomes of New Immigrants

Deborah A. Cobb-Clark

November 2004 


\title{
Selection Policy and the Labour Market Outcomes of New Immigrants
}

\author{
Deborah A. Cobb-Clark \\ SPEAR, RSSS, Australian National University \\ and IZA Bonn
}

Discussion Paper No. 1380

November 2004

\author{
IZA \\ P.O. Box 7240 \\ 53072 Bonn \\ Germany \\ Phone: +49-228-3894-0 \\ Fax: +49-228-3894-180 \\ Email: iza@iza.org
}

\begin{abstract}
Any opinions expressed here are those of the author(s) and not those of the institute. Research disseminated by IZA may include views on policy, but the institute itself takes no institutional policy positions.

The Institute for the Study of Labor (IZA) in Bonn is a local and virtual international research center and a place of communication between science, politics and business. IZA is an independent nonprofit company supported by Deutsche Post World Net. The center is associated with the University of Bonn and offers a stimulating research environment through its research networks, research support, and visitors and doctoral programs. IZA engages in (i) original and internationally competitive research in all fields of labor economics, (ii) development of policy concepts, and (iii) dissemination of research results and concepts to the interested public.
\end{abstract}

IZA Discussion Papers often represent preliminary work and are circulated to encourage discussion. Citation of such a paper should account for its provisional character. A revised version may be available directly from the author. 
IZA Discussion Paper No. 1380

November 2004

\title{
ABSTRACT \\ Selection Policy and the Labour Market Outcomes of New Immigrants
}

\begin{abstract}
Many countries are placing a greater emphasis on productive skills in the immigrant selection policies as a way of achieving national objectives regarding immigration. These changes stem primarily from the belief that skill-based immigrants do better in some sense and provide greater economic benefits than immigrants admitted on the basis of their family relationships. This paper takes advantage of a change in Australian selection policy in the 1990 s to assess the extent to which selection policy can facilitate employment outcomes for new arrivals over the medium run. The results indicate that the increased emphasis on productive skills in the selection process led to striking differences in the human capital endowments of new immigrants. These improvements in human capital in turn completely explain the higher participation rates amongst immigrants arriving in Australia at the end of the 1990s. Moreover, approximately half of the fall in men's unemployment rates also stems from increases in productive skills, though the substantial decline in women's unemployment rates are driven solely by changes in the returns to skills rather than skill levels themselves. Overall, these results indicate that there is a large potential for selection policy to influence immigrant outcomes not just immediately after migration but also in the medium run. At the same time, it is also clear that income-support policy and the overall state of the Australian labour market also had a hand in improving the labour market position of new arrivals.
\end{abstract}

JEL Classification: J61, J22, J20

Keywords: immigration, selection policy, unemployment, labour market participation

Deborah Cobb-Clark

SPEAR Centre, RSSS, Bld. 9

Australian National University

Canberra ACT, 0200

Australia

Email: deborah.cobb-clark@anu.edu.au 


\section{Introduction}

The increasing complexity of large-scale movements of people across international borders has policy makers grappling with difficult issues surrounding the design and implementation of policies meant to ensure that the potential benefits of immigration are realised for the host country. ${ }^{1}$ Selection policies - in which some potential immigrants are chosen over others - have historically been used in conjunction with quotas on the level of immigration as the primary means of achieving national objectives regarding immigration. Like Australia, other countries over the 1990s moved to place a greater emphasis on productive skills (including entrepreneurial skills) in the selection process. ${ }^{2} \quad$ These changes stem primarily from the belief that skill-based immigrants do better in some sense and provide greater economic benefits than immigrants admitted on the basis of their family relationships.

This chapter updates previous research exploring the potential for selection criteria, income-support policy and labour market conditions to facilitate entry into the Australian labour market (see Cobb-Clark, 2003). That research assessed initial outcomes (six months after migration) and concluded that the substantially improved outcomes for new arrivals over the 1990s resulted largely from changes in selection policy that led to enhanced skills amongst new immigrants. Still, changes in labour market conditions and income-support policy - which most likely altered the returns to human capital - appear to have been instrumental in reinforcing the effects of tighter selection criteria. This chapter reexamines these issues at a later stage -18 months after migration - of the settlement process. The question is: are immigrant outcomes over the longer run related to selection policy?

\footnotetext{
1 In particular, Stalker, (2000) estimates that the number of people worldwide living outside their country of birth now exceeds 120 million and more countries that ever are being classified as major suppliers or receivers of international migrants.
} 
Understanding the relationship between immigrant outcomes and selection criteria is important because the success of the migration decision rests for many immigrants on making a successful transition into the new labour market. Especially true in the early stages of settlement, this continues to be the case even in later stages of family reunion and community formation (Wooden, et al., 1994). It is, therefore, important to understand the capacity of immigrant selection policy to facilitate this transition. Selection policy also has implications beyond influencing outcomes for individual immigrants. By altering the skills of the immigrant flow - and consequently the extent to which immigrants and natives act as substitutes for one another - selection policy can affect macro employment and wage outcomes. Selection policy may also have fiscal effects if it is used to influence the extent to which new immigrants are likely to be reliant on the income-support system. Finally, selection policy is inherently bound up in the formation of attitudes towards immigrants, in attempts to achieve a range of other social and demographic goals, as well as the in political economy of decision making regarding immigration policy generally. ${ }^{3}$

The results indicate that the increased emphasis on productive skills in the selection process led individuals entering Australia in the late 1990s to have more education, better language skills, and more recent labour market experience than those individuals entering five years earlier. This expansion in skills explains completely explains the increased propensity for the second LSIA cohort to be labour market participants 18 months after migration. In contrast, the decline in unemployment - especially for women - is more closely related to differences in

\footnotetext{
2 See for example, Vialet and Eng (1990) for a discussion of the United States and Green and Green (1999) for a discussion of Canada.

${ }^{3}$ For example, a great deal of debate has centred on the extent to which immigration can be used to compensate for the effects of population aging (see for example, Straubhaar and Zimmermann, 1993; McDonald and Kippen, 2001; Withers, 2002) while Lazear (1998) considers the extent to which U.S. selection policy is successful in enhancing population diversity. A large literature also ties the formation of attitudes towards immigrants to
} 
the returns to productive characteristics that stem from changes in both income-support policy and aggregate labour market conditions. On the whole, however, up to two-thirds of the gap in the proportion of new arrivals who have found employment 18 months after migration stems from inter-cohort differences in productive skills. These patterns provide strong evidence that immigrant selection policy does influence immigrant outcomes not just immediately after migration, but also over the medium run.

This paper proceeds as follows. The literature on the relationship between selection policy and immigrant outcomes is reviewed in Section 2. Following that, issues related to the specific LSIA data sample and variable definitions used in this chapter are discussed. Section 4 compares the labour market outcomes and human capital endowments of new arrivals to Australia over the 1990s. Multivariate models of key outcomes are estimated and discussed in Section 5, while the decomposition analysis is presented in Section 6. Finally, a discussion of the results and the conclusions of the analysis are presented in Section 7.

\section{Selection Policy and Immigrant Outcomes}

Is selection policy a useful tool for capturing the potential economic gains - both to host nations and individual immigrants themselves - which could be derived from immigration? Many researchers in a number of different countries have addressed this question. The overarching conclusion is that selection criteria can be important in shaping immigration outcomes. However, while selection criteria - and settlement policy more broadly - can lead to improved economic outcomes, they may also have unintended effects.

immigration policy and the extent to which immigrants are seen to successfully integrate into the host country (see for example, Chiswick and Miller, 1999; Bauer, et al., 2000; Dustmann and Preston, 2000). 
Researchers have used the similarities in the Canadian, U.S., and (occasionally) Australian labour markets and the dissimilarities in their immigration policies to shed light on the ways in which selection criteria might matter (see Chiswick, 1987; Duleep and Regets, 1992; Borjas, 1993; Antecol, et al., 2003a; 2003b). These cross-national comparisons highlight the important role of the national origin mix in determining the skill level of the overall immigrant stream. Immigrants from newer source countries generally do less well than those from traditional sources (see Chiswick 1987 for example). The extent to which any differences in national origin mix stem from variation in immigrant selection policy is a matter of debate, however. Borjas (1993) concludes that the Canadian points system "attracted" more educated immigrants because it altered the national origin mix. At the same time, Antecol, et al., (2003a; 2003b) note that while much of the cross-national difference in immigrant skills does stem from the distribution across national origins, this distribution is similar for both men who are often selected on the basis of skills and women who are not. The authors conclude therefore that factors other than selection policy per se - i.e., geographic, historical, and or social forces contribute to producing the national origin mix of immigrants.

Selection policy has also been linked to both the initial occupational distribution and earnings of new arrivals. The introduction of the Canadian points system in 1967, for example, shifted the inflow of immigrants to Canada away from less skilled occupations (such as labourers) and towards professionals. However, subsequent changes in the entry-class and national-origin composition of immigrant admissions have reduced the tendency for immigrants to Canada to be assessed under the points system. ${ }^{4}$ At the same time, entry class matters. Skillbased immigrants are more likely to enter skilled occupations both in Canada (Green, 1995;

\footnotetext{
4 In effect, immigrants entering Canada in the "independent class" (who are points tested) are a residual category and are increasingly out numbered by immigrants in other classes (Green and Green, 1995; Green 1999).
} 
1999) and in the United States (Sorensen, et al., 1992; Jasso and Rosenzweig, 1995). Entry class is also related to immigrant earnings. Employment-based immigrants to the United States have higher initial earnings (Sorensen, et al., 1992; Duleep and Regets, 1996), while the fraction of individuals entering Canada as independent migrants is positively related to average entry wages (Wright and Maxim, 1993).

Although research indicates that selection criteria are almost certainly related to immigration outcomes, it is useful to bear in mind three observations regarding this relationship. First, selection criteria are most closely related to outcomes at the time of arrival and over time distinctions become less sharp. Jasso and Rosenzweig (1995) note, for example, that with time the occupational distribution of family- and skill-based immigrants becomes more similar, while Sorensen, et al. (1992) suggest that these two immigrant groups are actually quite similar in many respects including in their labour market attachment, their rate of naturalization, and their geographic distribution. Second, although more detailed individual-level survey data point to rather large differences in the outcomes of individuals in different visa categories, these differentials largely appear to reflect the underlying characteristics of immigrants themselves rather than immigrant categories per se (Miller, 1999; Cobb-Clark, 2000; 2003). This is especially true for established — as opposed to recent — immigrants. While the observable characteristics of individuals within visa categories do seem to be correlated, there is little unobserved heterogeneity associated with visa category. To the extent that migration programs operate by selecting individuals on the basis of readily observable characteristics, this is perhaps not surprising. Finally, policies beyond selection criteria also matter. Edin, et al. (2004) conclude, for example, that recent changes in immigrant settlement and integration policy in Sweden combined to produce substantial long-run earnings losses for immigrants. Earnings 
losses are primarily the result of the changed integration policy that reduced the focus on labour market assimilation and expanded access to the income-support system. New settlement policies mitigated these losses somewhat, however, by dispersing immigrants across more geographic areas.

\section{The Data Sample and Variables of Interest}

In order to focus attention on the effects of policy we need to draw comparisons between the two LSIA entry cohorts at a similar point in the settlement process. Consequently, this paper will focus solely on outcomes measured at wave 2, i.e., approximately 18 months after migration. ${ }^{5} \mathrm{~A}$ number of outcomes will be considered. Specifically, LSIA respondents were asked about their "current main activity". Individuations are coded as employed if they responded that their current main activity was working as a wage or salary earner or conducting a business. Labour market participants are employed individuals or individuals responding that they were unemployed and looking for either part-time or full-time work. ${ }^{6}$ Further, all LSIA respondents irrespective of current labour market status - were asked whether (and if so for how long) they had ever had ever been unemployed and looking for work since arriving in Australia. "Ever unemployed" is a dummy variable which equals one for individuals experiencing a period of unemployment since arrival and zero otherwise. "Months unemployed" captures - irrespective of current labour market status - the total duration of post-migration unemployment.

\footnotetext{
5 Unfortunately unlike Cohort 1 , Cohort 2 was only interviewed twice giving us no direct comparison between the cohorts later in the settlement process. For a similar analysis of outcomes six months after migration see CobbClark, 2003.

${ }^{6}$ Note that the LSIA measures of participation, employment, and unemployment differ from standard Australian Bureau of Statistics (ABS) definitions. As such, it is difficult to make comparisons between these results - in particular the unemployment rate - and those based on more standard definitions. This is not a particular problem for this analysis as it will be determinants of relative outcomes for different individuals that concern us.
} 


\section{The Labour Market Outcomes and Human Capital Endowments of New Arrivals}

Participation rates, employment-to-population ratios, and unemployment indicators for both cohorts are reported separately by gender and visa category in Table 1 . Cohort differences 18 months after migration largely mirror differences earlier in the settlement process (see CobbClark, 2003) and show the dramatic improvement in immigrants' early labour market outcomes over the latter half of the 1990s. Driven largely by the behaviour of immigrant women, there are large increases in the overall participation rate 18 months after migration from 57.2 per cent (Cohort 1) to 64.4 per cent (Cohort 2). At the same time, unemployment fell dramatically leading to a substantial improvement in the employment-to-population ratio. The unemployment rate of Cohort 2 immigrants ( 9.9 per cent) is less than half that of Cohort 1 immigrants $(22.3$ per cent) at the same stage of the settlement process. The end result is that somewhat less than half (44.4 per cent) of immigrants entering Australia between 1993 and 1995 had found employment 18 months after migration, while the employment-to-population ratio at the same point in the settlement process is 58.1 per cent for the cohort entering five years later. Finally, Cohort 2 immigrants are more likely to report experiencing some unemployment since arrival (59.9 per cent versus 56.8 per cent) - most likely the result of their greater tendency to enter the labour market - though on average immigrants arriving in Australia in the later part of the 1990s spent fewer months unemployed than did their counterparts who entered earlier. ${ }^{7}$

\section{Table 1 here}

Table 1 also documents the variation across visa categories in the participation rates and unemployment experiences of men and women in the two cohorts. In order to illustrate these differences, participation rates, unemployment rates, and employment-to-population ratios are

\footnotetext{
7 This occurred even though Cohort 2 immigrants had been in Australia somewhat longer on average at the interview date than Cohort 1 immigrants (see Table 2).
} 
shown in Figures $1-3$. Irrespective of the type of visa they held, Cohort 2 immigrants are much less likely to have been unemployed 18 months after arriving in Australia. The fall in unemployment is particularly impressive for Independent migrants - from 12.6 to 4.7 per cent for men and from 14.9 to 9.7 per cent for women - who were subject to the new points test, but is also evident for Family Stream and Humanitarian immigrants who were not. These falls in unemployment are even more impressive in light of the increased labour market participation rate that led proportionately more Cohort 2 immigrants to seek employment in the first place. The sole exception to the trend in improving labour market outcomes is the substantial fall in the participation rate (see Figure 1) of men and men and women holding Humanitarian visas. Though the probability of being unemployed - conditional on labour market entry - is also substantially lower, the fall in participation dominates leading the employment-to-population ratio for Humanitarian immigrants to be lower in Cohort 2 than in Cohort $1 .^{8}$

\section{Figures $1-3$ here}

Table 2 compares the productivity-related characteristics of the two LSIA cohorts. The distribution of LSIA immigrants across visa categories highlights the expansion of the skilled immigration program and the relative scaling back of the family and humanitarian streams. Amongst the immigrants interviewed at wave 2, the proportion who entered on a skills-based visa increased from one in three (35.2 per cent) in the first cohort to one in two (49.2 per cent) in the second. Individuals in the Family Stream accounted for 48.2 per cent of Cohort 1, but only 42.0 per cent of Cohort 2, while the proportion of Humanitarian immigrants fell by almost half over the five years separating the two entry cohorts.

\footnotetext{
8 Measured six months after migration the participation rate of ENS/BS immigrants fell from Cohort 1 to Cohort 2 while unemployment rates were relatively constant across cohorts (see Cobb-Clark, 2003). Eighteen months after migration these differences have been reversed with unemployment substantially lower and participation somewhat higher amongst those immigrants entering in the second half of the 1990s.
} 
Table 2 here

Though the demographic make up — average age, gender ratio, and marital status —of the two cohorts is much the same (see Table 2), there are striking differences in human capital endowments. Consistent with changes in selection criteria, the cohort of individuals entering Australia in 1999-2000 is more educated and has better English language skills ${ }^{9}$ than the previous cohort. In particular, native English speakers accounted for 42.3 per cent of Cohort 2 immigrants, but only 32.1 per cent of individuals entering in Cohort 1 . Immigrants in Cohort 2 are more likely to have been working in a professional occupation and less likely to have been not employed in their former home country in the year before migrating to Australia. ${ }^{10}$ Overall, almost half (46.0 per cent) of immigrants entering in 1999 - 2000 had recent labour market experience in a professional occupation at the time of migration. This was true of just over one third (35.1 per cent) of individuals in the first cohort. Finally, there are differences in the source countries of the two cohorts. Cohort 2 immigrants are more likely (55.6 per cent versus 48.9 per cent) to come from a country where English is widely spoken and with cultural traditions and institutions that closely resemble Australia's. ${ }^{11}$ These changes in human capital characteristics almost certainly facilitate employment and make the settlement process easier.

\footnotetext{
${ }^{9}$ LSIA respondents were asked to report about their ability to speak English. Those who reported speaking English "only" or "best" are classified as "native" English speakers. Non-native speakers who reported speaking English "very well" or "well" are combined to form the "English well" category. Non-native speakers who reported speaking English "badly" or "not at all" form the "English badly" category.

${ }^{10}$ Although LSIA data do not contain direct measures of labour market experience, LSIA respondents were asked about their labour market experiences in their former home country in the year prior to migration. Individuals employed at some point in the year prior to migration reported their occupation. These occupations have been coded into three major categories: professional, skilled, and unskilled. Individuals not employed in the 12 months before migration are coded as "not employed". Finally, "time unemployed" measures the number of months in the year prior to migration that an individual reported being unemployed and looking for work.

${ }^{11}$ In this analysis source countries are divided into English proficiency groups based on the English-speaking ability of recent immigrants to Australia (see DIMA, 1996). Group 1 includes the mainly English speaking countries (Canada, New Zealand, United Kingdom, Ireland, United States, and South Africa). Immigrants from these countries rate 98 per cent or higher on the English proficiency index. Group 2 includes those countries with a rating of 80 per cent or higher, while Group 3 includes countries with a rating between 50 per cent and 80 per cent. Countries with a rating of less than 50 per cent make up Group 4.
} 


\section{The Determinants of Labour Market Participation, Employment and Unemployment}

Our goal is to shed light on both the desire for employment and the success in finding it for immigrants in the two LSIA cohorts. To what extent were the changes in selection policy helpful in facilitating entry into the Australian labour market? In addressing this question, we will concentrate on three primary outcomes of interest to policy makers setting selection criteria: 1) the labour market participation rate; 2) the unemployment rate; and 3) the employment-topopulation ratio. In this section, multivariate models of the determinants of each of these labour market outcomes are estimated. These results will highlight the relationship between immigrants' skills and their early labour market outcomes. They will also form the basis of the decomposition analysis that follows in Section 6.

\subsection{The Empirical Framework}

We begin by modeling the process through which immigrants enter the Australian labour market and begin seeking work. In particular, immigrants are assumed to participate in the Australian labour market whenever the returns to market work exceed the value of their time in alternative activities. Modeling participation effectively allows us to draw distinctions between individuals who are and who are not economically active. Of course, not every new immigrant who wants a job will necessarily be successful in finding one. Some immigrants arrive in Australia with skills that do not completely translate into the Australian labour market. Making an investment in Australia-specific skills - for example, learning English - may increase the transferability of those skills acquired before migration (see Chiswick and Miller, 1994; Kahn, 1997; Duleep and Regets, 1999; Friedberg, 2000). Moreover, the efficiency of job search may 
depend both on the transferability of skills and on knowledge-which may be gained differentially over time - about the local institutions and work environment. Immigrants may need time to accumulate the skills - including labour market information - that are relevant to finding Australian employment. Given this, we also estimate the determinants of unemployment in order to understand how - conditional on having chosen to enter the Australian labour market - the characteristics of those who have been successful in finding employment 18 months after migration differ from those who have not. Finally, we consider the factors behind the propensity to be employed generally. Examining the employment-to-population ratio allows us to jointly consider the factors related to both desiring and successfully finding employment. ${ }^{12}$

Models of labour force participation and employment status 18 months after migration (wave 2) are estimated for male and female immigrants aged 22 - 60 using a standard probit model. ${ }^{13}$ Using the working-aged sample of labour market participants, the propensity to be unemployed is also estimated using a probit model. ${ }^{14}$ In each case, model 1 restricts the coefficients to be the same for each cohort allowing for only a simple intercept shift, while model 2 estimates separate slope coefficients for each cohort.

Each model includes a vector of human capital (education, English ability, English language background), demographic (age, marital status, children) and geographic (state of residence) variables thought to be related to the value of time in non-market activities and to labour market productivity. Although the data do not provide a direct measure of labour market experience, pre-migration occupation and employment status are included to take account of the

\footnotetext{
12 The employment-to-population ratio is in effect the product of the participation rate and one minus the unemployment rate.

13 All estimation was done in STATA 8.0. Results based on a random effects probit model are similar and are available from the author.

14 These outcomes are defined as discussed in Section3.
} 
effects of labour market experience immediately prior to migration. The model also includes controls for visa category, primary applicant status, and the number of weeks since migration.

The results (probit marginal effects and standard errors) from each regression are reported in Tables $3-5 .^{15}$ In addition, Tables $3-5$ report the results of $\mathrm{Chi}^{2}$ tests of significant differences in LSIA2 and LSIA1 coefficients. ${ }^{16}$ Given our focus on the potential role of public policy in facilitating labour market outcomes, we begin by considering relative outcomes across primary applicant and visa status. We then will explicitly consider the returns associated with those human capital characteristics (formal education, English language ability, and previous, recent labour market experience) that are most directly relevant for the immigrant selection process. This will shed light on the extent to which-by altering returns-changes in labour market conditions and income-support policy might have influenced outcomes for new arrivals to Australia.

Tables 3, 4 and 5 here

\subsection{The Immigration Process}

Eighteen months into the settlement process, women entering Australia between 1999 and 2000 have a participation rate that is 3.4 percentage points higher than otherwise similar women who migrated five years earlier. This inter-cohort differential in women's participation is much smaller when one conditions on individual characteristics (see Table 3) than when one does not

\footnotetext{
${ }^{15}$ Note that for continuous variables such as age, the probit marginal effect represents the effect of an infinitesimal change in the independent variable on the probability that an immigrant was in a specific labour market state. For discrete variables, such as marital status, the marginal effect represents the effect of a one-unit change in the independent variable. See the STATA manual for more details. Probit coefficients and robust standard errors are available upon request.

${ }^{16}$ These tests were conducted by estimating a fully interacted version of each of the equations. Coefficients on the interactions then reflect the difference in the determinants of the two cohorts. The results reported in Tables $3-5$ are the $\mathrm{p}$ values from the $\mathrm{Chi}^{2}$ tests of the significance of the interaction terms. Individual tests were performed for PA status and time since migration. Joint tests were performed for other subsets of variables.
} 
(see Table 1) suggesting that cohort differences in women's characteristics are an important part of the process leading to higher participation rates. Men in Cohort 2, on the other hand, have a significantly lower participation rate (3.0 percentage points) than men in Cohort 1 , a disadvantage that is larger at 18 months than at six months (see Cobb-Clark, 2003). This implies that improvements in participation between six and 18 months after migration were faster for men in Cohort 1. At the same time, both men and women entering Australia at the end of the 1990s had a much lower propensity to be unemployed relative to immigrants who entered earlier. ${ }^{17}$ Together these changes resulted in large increases in the proportion of new arrivals to Australia who had found employment a year and a half into the settlement process. The employment-to-population ratio was 9.8 percentage points higher for women in Cohort 2 and 7.7 percentage points higher for Cohort 2 men even after differences in productivity-related skills are taken into account.

Not surprisingly, primary applicants (who are subject to selection criteria) generally have higher participation and lower unemployment rates than spouses (who are not) (see Tables 3 and 4). Overall, women (men) entering as primary applicants are 13.5 (7.7) percentage points more likely to be employed 18 months after migration. Given that in 1999 additional points began to be awarded to those primary applicants whose spouses also met the minimum age, language, and skill requirements, it is also useful to focus on the inter-cohort difference in the employment advantage enjoyed by primary applicants relative to spouses. This advantage fell over time for women - as we might expect given the policy change - but increased over time for men, although these inter-cohort differences are not statistically significant (see Table 5).

\footnotetext{
${ }^{17}$ The magnitude of these differences 18 months after migration are much same as those at six months after migration for women, but considerably larger for men. In proportionate terms, however, these relative differences in unemployment are much more important 18 months after migration because the overall level of unemployment (the base) is much smaller.
} 
Diversity in labour market experiences across visa categories is particularly informative about the role of selection criteria in facilitating labour market entry. The following discussion will focus on the employment-to-population ratio in order to illustrate the key results (see Table 5). The omitted category in each of the models is individuals holding a ENS/BS visa and all of the results are interpreted relative to this group. It is striking that 18 months into the settlement process there are no significant differences in the propensity for skills-based women (i.e., ENS/BS, SAL, or Independent migrants) in either Cohort 1 or Cohort 2 to be employed, though both family-based and humanitarian women have significantly lower employment-to-population ratios. The lack of variation in outcomes across women holding a range of immigration visas may not be particularly surprising given that the points test is generally used to select men rather than women who disproportionately enter as accompanying family members for whom no selection criteria apply. ${ }^{18}$ At the same time, the results clearly point to a deterioration in the relative position of humanitarian women across the two cohorts. Women entering Australia on a Humanitarian visa between 1993 and 1995 were 10.3 percentage points less likely to be employed 18 months after migration. This disadvantage more than doubled to 27.5 percentage points amongst women entering five years later.

Differences in the employment experiences of men holding ENS/BS visas and other men are much sharper. Men entering Australia in the first half of the 1990s on the basis of prearranged employment (ENS) or their business skills (BS) had more than a 20 percentage point employment advantage over other skills-based and family immigrants and an almost 50 percentage point advantage over men selected out of humanitarian concerns. This advantage relative to SAL immigrants fell over time (though the change is not quite significant), but

\footnotetext{
${ }^{18}$ Only 5.4 per cent of all female immigrants to Australia in 1990-1991 entered as primary applicants in one of the skill-based programs (Madden and Young, 1993). Women also tend to be over-represented in family classes and
} 
widened significantly (to 65.4 percentage points) relative to humanitarian immigrants. This widening gap is not the result of large improvements in the outcomes of ENS/BS immigrantstheir employment-to-population ratio increased only slightly (see Table 1)-but rather to the worsening position of humanitarian immigrants. ${ }^{19}$

\subsection{Human Capital Endowments}

Focusing on cohorts' returns to labour market skills informs us about the extent to which changes in Australian labour market conditions and income-support policy over the 1990s may have affected new immigrants' labour market outcomes. Let us begin by considering changes in the return to formal education. In each of the case, those individuals who have completed 12 years of schooling, but who have not continued on to university, are the omitted category and all results are interpreted relative to this group. There is no evidence that the returns to education changed for women over the 1990s. Inter-cohort differences in female returns to education are neither individually nor jointly significant for any of the three outcomes under consideration. ${ }^{20}$ There are significant changes in the returns to education for male immigrants, however. The labour market advantage enjoyed by relatively education men increased, while the penalties associated with currently being enrolled in formal education decreased. We cannot separately identify the effects of labour market conditions themselves from the effects of income-support policy - which most likely affects the incentives to find employment - in producing these

under-represented in skill classes in Canada and the United States (Houstoun, et al., 1984; UN, 1995).

19 It is important to note that this relative deterioration occurs despite accounting for a range of productive skills in the regression model. At the same time, other factors omitted from the regression model may contribute to producing this effect. In particular, although more than a third (35.9 per cent) of Humanitarian migrants in Cohort 1 came from Europe and the former Soviet Union, this was true of less than 1 per cent of Humanitarian migrants in Cohort 2. Humanitarian migrants entering Australia in the late 1990s were more than twice as likely (44.2 versus 20.5 per cent) to come from the Middle East or Africa.

${ }^{20}$ Results of the joint significance tests are given in Tables $3-5$. 
changing returns to education. Still, tighter access to a range of income-support options would be expected to have a direct effect on students' incentive to find employment while studying.

While the penalty for having relatively little education increased over the 1990s, the employment penalty for not speaking English well actually decreased so that there were fewer differences in outcomes for individuals with differing levels of English language ability. ${ }^{21}$ As with changes in the returns to education, changes in returns to English language ability were more evident for men. Men who entered Australia in 1993 - 1995 and were not native English speakers faced substantial penalties in terms of lower participation and higher unemployment 18 months after migration (see Tables 3-5). These penalties disappeared for men who entered Australia five years later. For example, men in Cohort 1 who reported speaking English badly had an unemployment rate that was 13.1 percentage points higher than native English speakers. In contrast, Cohort 2 men who spoke English badly had the same propensity to be unemployed as men who were native English speakers. In fact, there is no evidence that language ability is significantly related to either the participation or unemployment experiences of men entering Australia at the end of the 1990s. ${ }^{22}$

While education and English language ability dominate the story for men, it is premigration labour market experiences that are particularly salient for women. There was a dramatic increase over the 1990s in the extent to which a woman's labour market attachment immediately prior to migration was useful in predicting whether she had chosen to enter the Australian labour market a year and a half after arrival. Cohort 2 women who were employed as professionals in the year before migration were a 23.4 percentage points more likely to be labour

\footnotetext{
${ }^{21}$ Here native English speakers are the omitted category.

${ }^{22}$ Similar trends are observed for women, though there is evidence that poor English skills continued to be a barrier to women's labour market participation - and hence employment probability - throughout the 1990s.
} 
market participants than similar women who were not employed at all prior to migration. Amongst Cohort 1 women this difference was only 7.4 percentage points. Interestingly, the stronger link over time between pre- and post-migration outcomes is apparent for participation and hence employment - but not unemployment outcomes. It is also apparent only for women leaving the relationship between previous and current employment outcomes much the same for men irrespective of when they entered Australia.

\section{Decomposing the Differences in Cohort Outcomes}

To what extent are changes in immigrant selection policy the source of Cohort 2's improved labour market outcomes? What role do labour market conditions and income-support policy have in facilitating immigrants' entry into the Australian labour market? To address these questions, we decompose relative improvements in the participation, unemployment, and employment-to-population rates of new arrivals in Australia into characteristics-related and returns-to-characteristics-related components. Generally speaking, we expect that the influence of changes in immigration policy will have its most direct effect on changes in characteristics themselves, while labour market conditions and income-support policy work most directly to alter the Australian labour market returns to characteristics.

The discrete (yes/no) nature of the participation, unemployment, and employment outcomes in which we are interested leads us to use probit estimation (see Section 5). However, the non-linearity of the cumulative normal distribution - upon which the probit model is based implies that standard linear decompositions are not possible. Given this, we follow a decomposition procedure based upon a linear approximation that has been suggested by Doiron

Conditional on labour market entry, however, language ability is not significantly related to the unemployment experiences 18 months after migration of women in the second LSIA cohort. 
and Riddell (1994) and is outlined in detail in the appendix. ${ }^{23}$ This decomposition is not unique and as always depends on whose returns (Cohort 1's or Cohort 2's) we choose to use to weight the differences in average characteristics. Results based on both sets of weights are presented in Table 6.

\section{Table 6 Here}

Men and women entering Australia in 1999 - 2000 (Cohort 2) had labour market participation rates eighteen months into the settlement process that were higher (3.4 and as 9.9 percentage points respectively) than immigrants entering in $1993-1995$. Most - if not all - of this difference is due to differences in the demographic and productivity-related characteristics underlying the participation decision itself. Between 75.0 and 94.5 per cent of the inter-cohort difference for women is due to differences in the average characteristics of cohort members. Moreover, differences in cohort characteristics more than explain the disparity in the participation rates of men, implying that if Cohort 2 men had faced the same labour market returns that Cohort 1 men did their participation advantage would have been even greater.

In contrast, inter-cohort differentials in the propensity to be unemployed 18 months after migration - given that one has chosen to seek work - are largely driven by the return to productive characteristics. Differences in returns completely explain the 12.5 percentage point decline in the unemployment rate of women and explain between 57.4 and 65.0 per cent of the 12.9 percentage point fall in the unemployment rate of men. Consistent with gender differences in the source of inter-cohort participation gaps, disparities in human capital endowments play a larger role (between 43.8 and 51.4 per cent) in explaining the fall in male unemployment rates.

\footnotetext{
${ }^{23}$ Unlike the standard linear case, a proportion of the difference in average outcomes will be attributable to the approximation itself.
} 
This is not particularly surprising given that men are disproportionately more likely to be subject to the selection criteria (see Table 2).

Overall, approximately two-thirds of the gap in the proportion of men who have found employment one and a half years into the settlement process stems from inter-cohort differences in their demographic and human capital characteristics. For women, characteristics account for between half and two-thirds of the gap.

\section{Discussion and Conclusions}

The increased emphasis on productive skills in the procedures Australia used to select new immigrants in the late 1990s led to striking differences in the human capital endowments of new arrivals. Though the demographic composition (i.e., average age, gender ratio, and marital status) of immigrants remained much the same, individuals entering Australia in 1999-2000 had more education, better English language skills and more pre-migration labour market experience skills than did their predecessors. These improvements in human capital endowments completely explain the higher participation rates amongst immigrants arriving in Australia at the end of the 1990s. Moreover, approximately half of the fall in men's unemployment rates also stems from increases in productive skills, though the substantial decline in women's unemployment rates are driven solely by changes in the returns to skills rather than skill levels themselves.

These results indicate that there is a large potential for immigrant selection policy to influence immigrant outcomes not just immediately after migration but in the medium run. Changes in immigrant skills are consistent with those policy changes that gave greater emphasis to educational qualification, language ability, and recent labour market experience. Moreover, men are much more likely than women to be actually be assessed under the prevailing selection 
criteria and so it is perhaps not surprising that changes in characteristics are more directly responsible for improvements in male than in female labour market outcomes.

At the same time, it is also clear that income-support policy and the overall state of the Australian labour market had a hand in the improved labour market position of those arriving between 1999 and 2000. Women in the second LSIA cohort were simply more attached to the Australian labour market than their predecessors. In particular, women in Cohort 2 were much more likely to have recent, pre-migration labour market experience in a profession - an effect which is most likely attributable to changes in selection policy. However - conditional on having pre-migration experience - they were also substantially more likely to have entered the Australian labour market a year and a half into the settlement process. This latter effect results from changes in the returns to (rather than in the level of) pre-migration experience. Unfortunately, it is difficult to know whether it arises because the inability to access the incomesupport system pushed more women into the Australian labour market in order to support their families or whether increased wage returns for previous experience encouraged more women to seek employment.

The changing rewards to skills are an important part of the story for men as well. These changes seem to have opened up employment opportunities for men who do not speak English well. In particular, there is no evidence that language ability is significantly related to either the participation or unemployment experiences of men entering Australia at the end of the 1990s. Moreover, men in the second LSIA cohort who were enrolled in formal education 18 months after migration were much more likely to be combining that education with employment. Again it is unclear whether this stems from changes in employment conditions that opened up 
employment opportunities for these men or is due to the disappearance of the income-support safety net.

In the context of the broader story it is important to take special note of the worsening position of humanitarian immigrants. Though their numbers declined proportionately (from 16.6 to 8.8 per cent), their story is a striking exception to the overall positive picture painted here. Humanitarian immigrants entering as part of the second LSIA cohort were simply much less likely to have entered the Australian labour market 18 months after migration. Although the probability of being unemployed - conditional on labour market entry - is also substantially lower, the fall in participation dominates leading the employment-to-population ratio for humanitarian migrants to be lower in Cohort 2 than in Cohort 1. These changes occurred despite the fact that Australian immigration policy with respect to refugees remained largely unchanged. It seems likely that push factors - which may have altered the characteristics of the Humanitarian stream - are also important in understanding outcomes for refugees.

Overall Australian selection policy was largely successful in selecting immigrants whose skills led them to be more inclined to seek out employment, while changes in labour market conditions and income-support policy over the intervening period contributed to making them more likely to get it. These patterns 18 months into the settlement process largely - though not completely - confirm those observed immediately after migration. Six months after migration, inter-cohort differentials in human capital characteristics accounted for the majority of the difference in cohorts' unemployment experiences. Twelve months on variation in labour market returns play a much larger role in generating inter-cohort disparities in unemployment (though not participation). These differences in returns are the result of a complex interaction between changes in income-support policies that affected individuals' incentives to search for jobs and 
changes in labour market conditions which affected their ability to find them. Unfortunately, it is not possible to definitively isolate the two effects. 


\section{REFERENCES}

Antecol, Heather, Deborah A. Cobb-Clark, and Stephen J. Trejo, 2003a. "Immigration Policy and the Skills of Immigrants to Australia, Canada, and the United States", Journal of Human Resources, 38(1), Winter 2003, pp. $192-21$.

, 2003b, "The Skills of Female Immigrants to Australia, Canada, and the United States", Host Societies and the Reception of Immigrants, Jeffrey G. Reitz (ed.), San Diego: Center for Comparative Immigration Studies, forthcoming.

Bauer, Thomas, Magnus Lofstom, and Klaus F. Zimmermann, 2000. "Immigration Policy, Assimilation of Immigrants, and Natives' Sentiments Towards Immigrants: Evidence from 12 OECD Countries", Swedish Economic Policy Review, Vol. 7(2), Fall, pp. 11- 53.

Borjas, George. J., 1993. "Immigration Policy, National Origin, and Immigrant Skills: A Comparison of Canada and the United States" in Small Differences that Matter: Labor Markets and Income Maintenance in Canada and the United States. David Card and Richard Freeman, editors. Chicago: University of Chicago Press: 21 - 44.

Chiswick, Barry R., 1987. "Immigration Policy, Source Countries, and Immigrant Skills: Australia, Canada, and the United States" in The Economics of Immigration. Proceedings of Conference held at the Australian National University. Canberra: Australian Government Printing Service.

Chiswick, Barry R. and Paul W. Miller, 1999. "Immigration, Language and Multiculturalism in Australia”, Australian Economic Review, Vol. 32(4), December, pp. 369-385.

1994, "The Determinants of Post-Immigration Investments in Education," Economics of Education Review, 13(2): 163-177.

Cobb-Clark, Deborah A., 2000 "Do Selection Criteria Make a Difference? Visa Category and the Labor Market Status of Immigrants to Australia. The Economic Record, 76(232), March.

2003. "Public Policy and the Labor Market Adjustment of New Immigrants to Australia", Journal of Population Economics, 16, pp. 655-681.

Doiron, Denise J. and W. Craig Riddell, 1994. "The Impact of Unionization on Male-Female Earnings Differences in Canada", Journal of Human Resources, Vol. XXIX(2), Spring, pp. 504-534.

Duleep, Harriet Orcutt and Mark C. Regets, 1992. "Some Evidence on the Effects of Admissions Criteria on Immigrant Assimilation" in Immigration, Language and Ethnic Issues: Canada and the United States. Barry R. Chiswick, editor. Washington: American Enterprise Institute: 410 - 439. 
------- 1996. “Admission Criteria and Immigrant Earnings Profiles.” International Migration Review 30(2): 571 - 590.

1999, "Immigrants and Human-Capital Investment" American Economic Review vol.89 no.2, 186-190.

Dustmann, Christian and Ian Preston, 2000. "Racial and Economic Factors in Attitudes to Immigration", CEPR Discussion Paper 2542.

Edin, Per-Anders, Peter Fredriksson, and Olof Åslund, 2004. "Settlement Policies and the Economic Success of Immigrants”, Journal of Population Economics, 17, pp. 133- 155.

Friedberg, Rachel M., 2000. "You Can't Take It with You? Immigrant Assimilation and the Portability of Human Capital" Journal of Labor Economics, vol. 18, no.2, 221-251.

Green, David A., 1995. "Intended and Actual Occupations of Immigrants" in Diminishing Returns: The Economics of Canada's Recent Immigration Policy, D. J. DeVortez, editor. Toronto and Vancouver: C.D. Howe Institute and The Laurier Institution.

1999. "Immigrant Occupational Attainment: Assimilation and Mobility over Time", Journal of Labor Economics, Vol. XXV, No. 4, pp. 425 - 451.

Green, Alan G. and David A. Green, 1995. "Canadian Immigration Policy: The Effectiveness of the Point System and Other Instruments", The Canadian Journal of Economics, Vol. 28(4b), November, pp. 1006-1041.

------- 1999. "The Economics Goals of Canada's Immigration Policy: Past and Present", Canadian Public Policy, Vol. XXV, No. 4, pp. 425 - 451.

Houstoun, Marion F., Roger G. Kramer, and Joan Mackin Barrett, 1984. "Female Predominance in Immigration in the United States Since 1930: A First Look", International Migration Review, Vol. 38 (4), pp. $908-963$.

Jasso, Guillermina and Mark R. Rosenzweig (1995). "Do Immigrants Screened for Skills Do Better than Family Reunification Immigrants?" International Migration Review 29(1), pp. 85- 111.

Khan, Aliya Hashmi, 1997. "Post-Migration Investment in Education by Immigrants in the United States," The Quarterly Review of Economics and Finance, vol.37, Special Issue, 285-313. 
Lazear, Edward P., 1998. "Diversity and Immigration”, NBER Working Paper, 6535, April 1998.

Madden, Ros and Susan Young, 1993. Women and Men Immigrating to Australia: Their Characteristics and Immigration Decisions, Bureau of Immigration Research, Canberra : Australian Government Publishing Service.

McDonald, Peter and Rebecca Kippen, 2001. "The Impact of Immigration on the Ageing of Australia's Population" in International Migration into the Twenty-First Century: Essays in Honour of Reginald Appleyard, pp. 153-177.

Miller, Paul W., 1999. "Immigration Policy and Immigrant Quality: The Australian Point System", American Economic Review, Vol. 89(2), May, pp. 192 - 197.

Sorensen, Elaine, Frank D. Bean, Leighton Ku, and Wendy Zimmermann, 1992. Immigrant Categories and The U.S. Job Market: Do They Make a Difference? Washington: The Urban Institute Press.

Stalker, Peter (2000). Workers Without Frontiers: The Impact of Globalization on International Migration, Boulder, CO: Lynne Rienner Publishers, Inc.

Straubhaar, Thomas and Klaus F. Zimmermann, 1993. "Towards a European Migration Policy", Population Research and Policy Review, Vol. 12 (3), pp. 225-241.

United Nations (UN), Department for Economic and Social Information and Policy Analysis, Population Division, 1995. International Migration Policies and the Status of Female Migrant, New York: United Nations.

Vialet, Joyce C. and Larry M. Eig, 1990. Immigration Act of 1990 (P.L. 101-649). Washington: Congressional Research Service, Library of Congress.

Withers, Glenn, 2002. "Population Ageing and the Role of Immigration", Australian Economic Review, Vol. 35(1), March, pp. 104-112.

Wooden, Mark, Holton, R., Hugo, G., and J. Sloan. (1994) Australian Immigration: A Survey of the Issues, Canberra: Australian Government Printing Service.

Wright, Robert E. and Paul S. Maxim, 1993. "Immigration Policy and Immigrant Quality: Empirical Evidence from Canada", Journal of Population Economics, 6, pp. 337 - 352. 
Table 1: Labour Market Outcomes 18 Months After Migration First and Second LSIA Cohorts by Gender and Visa Category

(Means ${ }^{\mathrm{a}}$ and Standard Deviations)

\begin{tabular}{|c|c|c|c|c|c|}
\hline & $\begin{array}{c}\text { Participation } \\
\text { Rate }\end{array}$ & $\begin{array}{c}\text { Unemployment } \\
\text { Rate }\end{array}$ & $\begin{array}{c}\text { Employment } \\
\text { to Population } \\
\text { Ratio }\end{array}$ & $\begin{array}{c}\text { Months } \\
\text { Unemployed }\end{array}$ & $\begin{array}{c}\text { Proportion } \\
\text { Ever } \\
\text { Unemployed }\end{array}$ \\
\hline & Mean (Std.) & Mean (Std.) & Mean (Std.) & Mean (Std.) & Mean (Std.) \\
\hline \multicolumn{6}{|l|}{ Total } \\
\hline Cohort 1 & $0.572(0.495)$ & $0.223(0.416)$ & $0.444(0.497)$ & 2.805 (4.013) & $0.568(0.495)$ \\
\hline Cohort 2 & $0.644(0.479)$ & $0.099(0.298)$ & $0.581 \quad(0.494)$ & $2.295(3.766)$ & $0.599(0.490)$ \\
\hline \multicolumn{6}{|l|}{ Men } \\
\hline Cohort 1 & $0.786(0.410)$ & $0.224(0.417)$ & $0.610(0.488)$ & 3.295 (4.117) & $0.620(0.486)$ \\
\hline Cohort 2 & $0.819(0.385)$ & $0.100(0.300)$ & $0.737(0.440)$ & $2.616(3.997)$ & $0.636(0.481)$ \\
\hline \multicolumn{6}{|l|}{ Women } \\
\hline Cohort 1 & $0.396(0.489)$ & $0.222(0.416)$ & $0.308(0.462)$ & $2.400(3.879)$ & $0.525(0.499)$ \\
\hline Cohort2 & $0.495(0.500)$ & $0.096(0.295)$ & $0.448(0.497)$ & $2.026(3.540)$ & $0.567(0.496)$ \\
\hline \multicolumn{6}{|l|}{ Men Cohort 1} \\
\hline Family & $0.726(0.446)$ & $0.197(0.398)$ & $0.583(0.493)$ & $2.816(3.897)$ & $0.552(0.498)$ \\
\hline SAL & $0.881 \quad(0.325)$ & $0.185(0.389)$ & $0.717(0.451)$ & 3.377 (3.807) & $0.754(0.431)$ \\
\hline BS/ENS & $0.934(0.248)$ & $0.037(0.189)$ & $0.899(0.301)$ & $0.380(1.434)$ & $0.240(0.427)$ \\
\hline Independent & $0.901 \quad(0.299)$ & $0.126(0.332)$ & $0.788(0.409)$ & $2.864(3.549)$ & $0.725(0.447)$ \\
\hline Humanitarian & $0.656(0.475)$ & $0.568(0.496)$ & $0.283(0.451)$ & $5.644(4.859)$ & $0.644(0.479)$ \\
\hline \multicolumn{6}{|l|}{ Men Cohort 2} \\
\hline Family & $0.791(0.407)$ & $0.147(0.355)$ & $0.674(0.469)$ & $3.340(4.789)$ & $0.627(0.484)$ \\
\hline SAL & $0.927(0.262)$ & $0.063(0.243)$ & $0.868(0.339)$ & $2.704(3.269)$ & $0.845(0.363)$ \\
\hline BS/ENS & $0.915(0.279)$ & $0.003(0.052)$ & $0.913(0.283)$ & 0.767 (2.639) & $0.230(0.422)$ \\
\hline Independent & $0.894(0.308)$ & $0.047(0.212)$ & $0.852(0.355)$ & $1.606(2.327)$ & $0.664(0.473)$ \\
\hline Humanitarian & $0.403(0.491)$ & $0.489(0.502)$ & $0.206(0.405)$ & $4.741(5.517)$ & $0.589(0.492)$ \\
\hline \multicolumn{6}{|l|}{ Women Cohort 1} \\
\hline Family & $0.356(0.479)$ & $0.230(0.421)$ & $0.274(0.446)$ & $2.169(3.666)$ & $0.425(0.495)$ \\
\hline SAL & $0.571 \quad(0.495)$ & $0.221(0.415)$ & $0.445(0.497)$ & $2.934(3.966)$ & $0.752(0.432)$ \\
\hline BS/ENS & $0.408(0.492)$ & $0.060(0.238)$ & $0.384(0.487)$ & $1.009(2.591)$ & $0.277(0.448)$ \\
\hline Independent & $0.548(0.466)$ & $0.149 \quad(0.357)$ & $0.149(0.357)$ & $2.344(3.719)$ & $0.738(0.440)$ \\
\hline Humanitarian & $0.265(0.442)$ & $0.422(0.496)$ & $0.153(0.360)$ & $3.421(4.776)$ & $0.592(0.492)$ \\
\hline \multicolumn{6}{|l|}{ Women Cohort 2} \\
\hline Family & $0.452(0.498)$ & $0.113(0.318)$ & $0.401 \quad(0.490)$ & $2.179(3.541)$ & $0.491(0.500)$ \\
\hline SAL & $0.700(0.460)$ & $0.053(0.225)$ & $0.662(0.474)$ & $3.176(4.313)$ & $0.830(0.377)$ \\
\hline BS/ENS & $0.456(0.499)$ & $0.005(0.072)$ & $0.454(0.499)$ & 0.627 (1.867) & $0.224(0.418)$ \\
\hline Independent & $0.625(0.485)$ & $0.097(0.296)$ & $0.565(0.497)$ & $1.751(3.297)$ & $0.708(0.456)$ \\
\hline Humanitarian & $0.115(0.319)$ & $0.324(0.473)$ & $0.077(0.268)$ & $1.602(3.671)$ & $0.504(0.501)$ \\
\hline
\end{tabular}

${ }^{\mathrm{a}}$ All means are in per cents except months unemployed. See Section 4 for variable definitions. 
Table 2: Visa Status, Demographic, and Human Capital Characteristics 18 Months After Migration LSIA Immigrants by Gender and Cohort

(Means ${ }^{\mathrm{a}}$ and Standard Deviations)

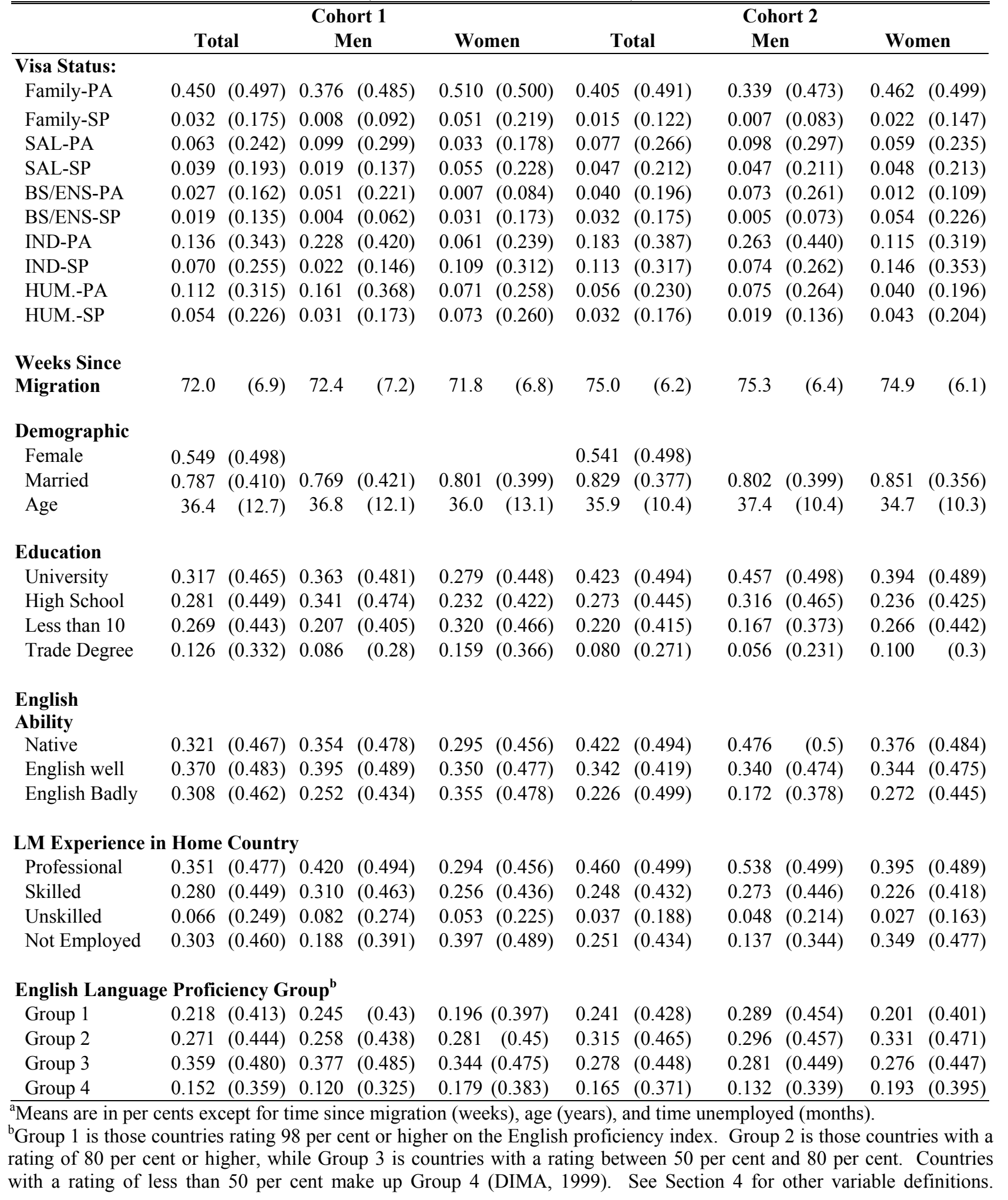




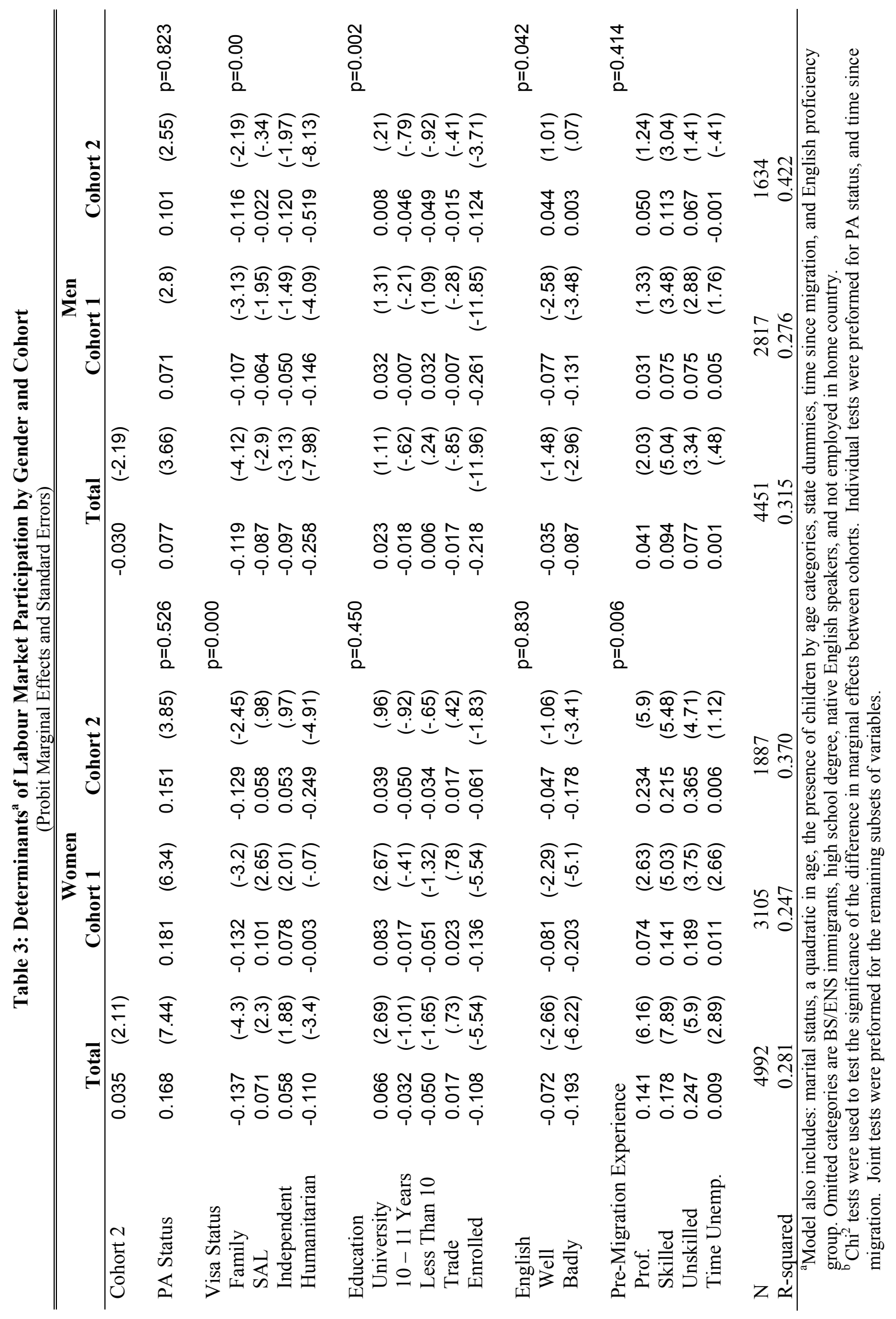




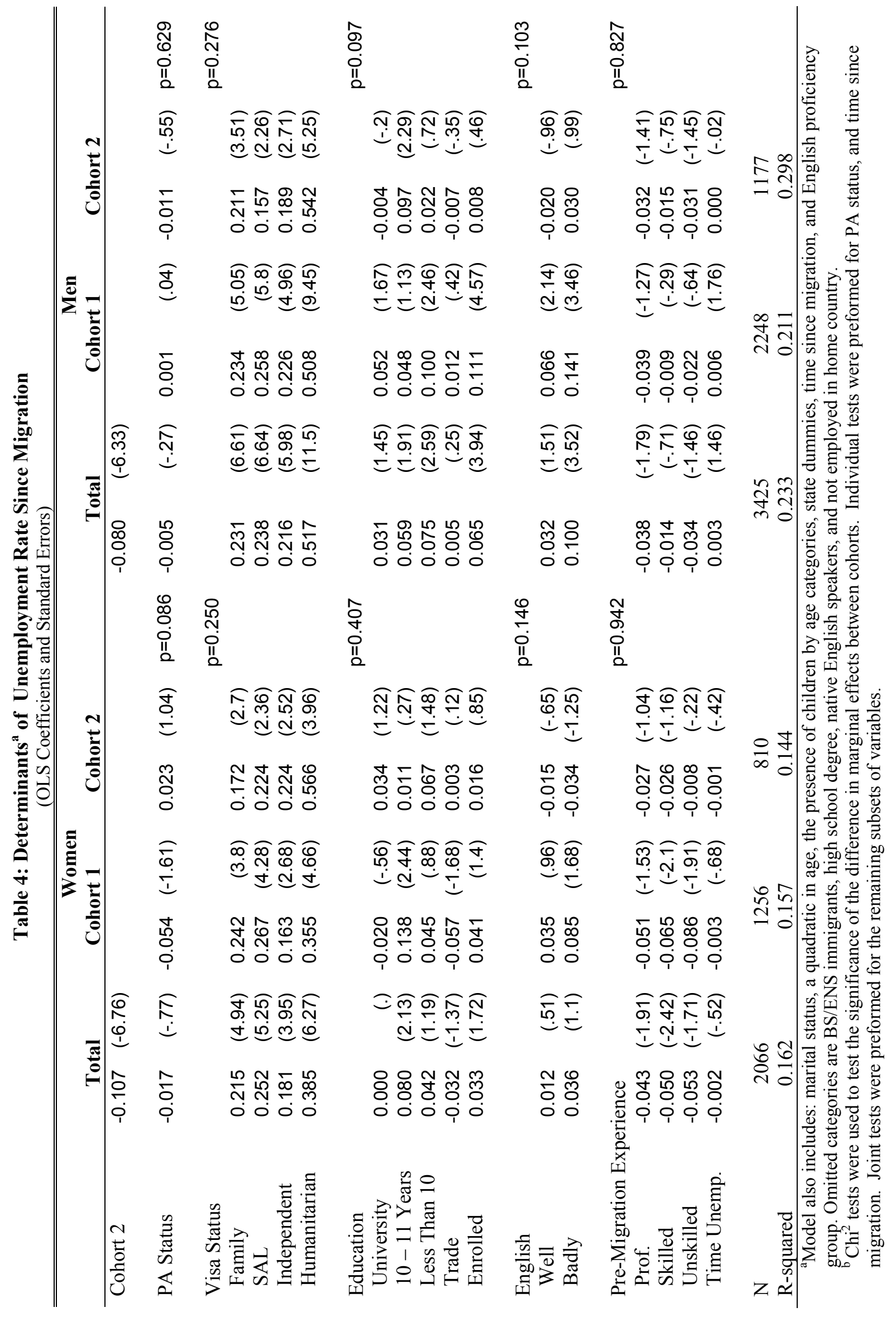




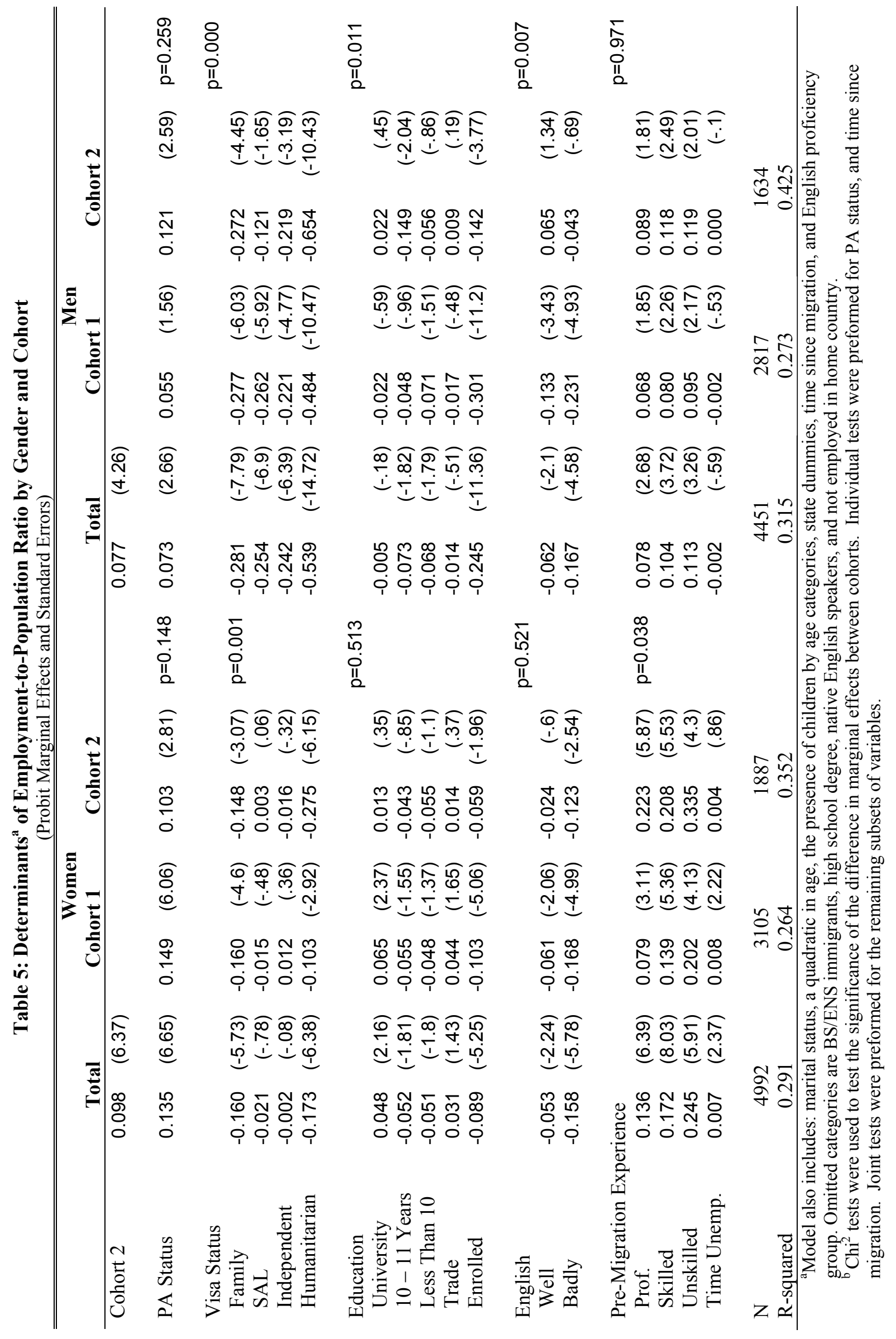


Table 6: Decomposition of Cohort Gap in Labour Market Status and Unemployment Experience

\begin{tabular}{|c|c|c|c|c|}
\hline \multirow[b]{3}{*}{ Labour Market Participation } & \multicolumn{4}{|c|}{ Women } \\
\hline & \multicolumn{2}{|c|}{ Decomposition 1} & \multicolumn{2}{|c|}{ Decomposition 2} \\
\hline & Level & Per cent & Level & Per cent \\
\hline Difference (Cohort 2 - Cohort1) & 0.099 & & 0.099 & \\
\hline Characteristics & 0.093 & 0.945 & 0.074 & 0.750 \\
\hline Returns & 0.005 & 0.053 & 0.024 & 0.248 \\
\hline \multirow[t]{2}{*}{ Approximation } & \multirow[t]{2}{*}{0.001} & 0.002 & \multirow[t]{2}{*}{0.001} & 0.002 \\
\hline & & 100.0 & & 100.0 \\
\hline Unemployment Rate & Level & Per cent & Level & Per cent \\
\hline Difference (Cohort 2 - Cohort 1) & -0.125 & & -0.125 & \\
\hline Characteristics & -0.009 & 0.075 & 0.010 & -0.081 \\
\hline Returns & -0.123 & 0.984 & -0.143 & 1.140 \\
\hline \multirow[t]{2}{*}{ Approximation } & \multirow[t]{2}{*}{0.007} & -0.059 & \multirow[t]{2}{*}{0.007} & -0.059 \\
\hline & & 100.0 & & 100.0 \\
\hline Employment-to-Population Ratio & Level & Per cent & Level & Per cent \\
\hline Difference (Cohort $2-$ Cohort 1) & 0.139 & & 0.139 & \\
\hline Characteristics & 0.091 & 0.658 & 0.072 & 0.520 \\
\hline Returns & 0.046 & 0.332 & 0.065 & 0.470 \\
\hline \multirow[t]{4}{*}{ Approximation } & \multirow[t]{2}{*}{0.002} & 0.010 & \multirow[t]{2}{*}{0.002} & 0.010 \\
\hline & & 100.0 & & 100.0 \\
\hline & \multicolumn{4}{|c|}{ Men } \\
\hline & \multicolumn{2}{|c|}{ Decomposition 1} & \multicolumn{2}{|c|}{ Decomposition 2} \\
\hline Labour Market Participation & Level & Per cent & Level & Per cent \\
\hline Difference (Cohort 2 - Cohort 1$)$ & 0.034 & & 0.034 & \\
\hline Characteristics & 0.043 & 1.251 & 0.048 & 1.396 \\
\hline Returns & -0.008 & -0.237 & -0.013 & -0.381 \\
\hline \multirow[t]{2}{*}{ Approximation } & \multirow[t]{2}{*}{-0.001} & -0.014 & \multirow[t]{2}{*}{-0.001} & -0.014 \\
\hline & & 100.0 & & 100.0 \\
\hline Unemployment Rate & Level & Per cent & Level & Per cent \\
\hline Difference (Cohort 2 - Cohort 1) & -0.129 & & -0.129 & \\
\hline Characteristics & -0.056 & 0.438 & -0.075 & 0.514 \\
\hline Returns & -0.084 & 0.650 & -0.104 & 0.574 \\
\hline \multirow[t]{2}{*}{ Approximation } & \multirow[t]{2}{*}{0.011} & -0.088 & \multirow[t]{2}{*}{0.013} & -0.088 \\
\hline & & 100.0 & & 100.0 \\
\hline Employment-to-Population Ratio & Level & Per cent & Level & Per cent \\
\hline Difference (Cohort 2-Cohort 1) & 0.133 & & 0.133 & \\
\hline Characteristics & 0.086 & 0.645 & 0.090 & 0.680 \\
\hline Returns & 0.051 & 0.382 & 1.046 & 0.347 \\
\hline \multirow[t]{2}{*}{ Approximation } & \multirow[t]{2}{*}{-0.004} & -0.027 & \multirow[t]{2}{*}{-0.004} & -0.027 \\
\hline & & 100.0 & & 100.0 \\
\hline
\end{tabular}




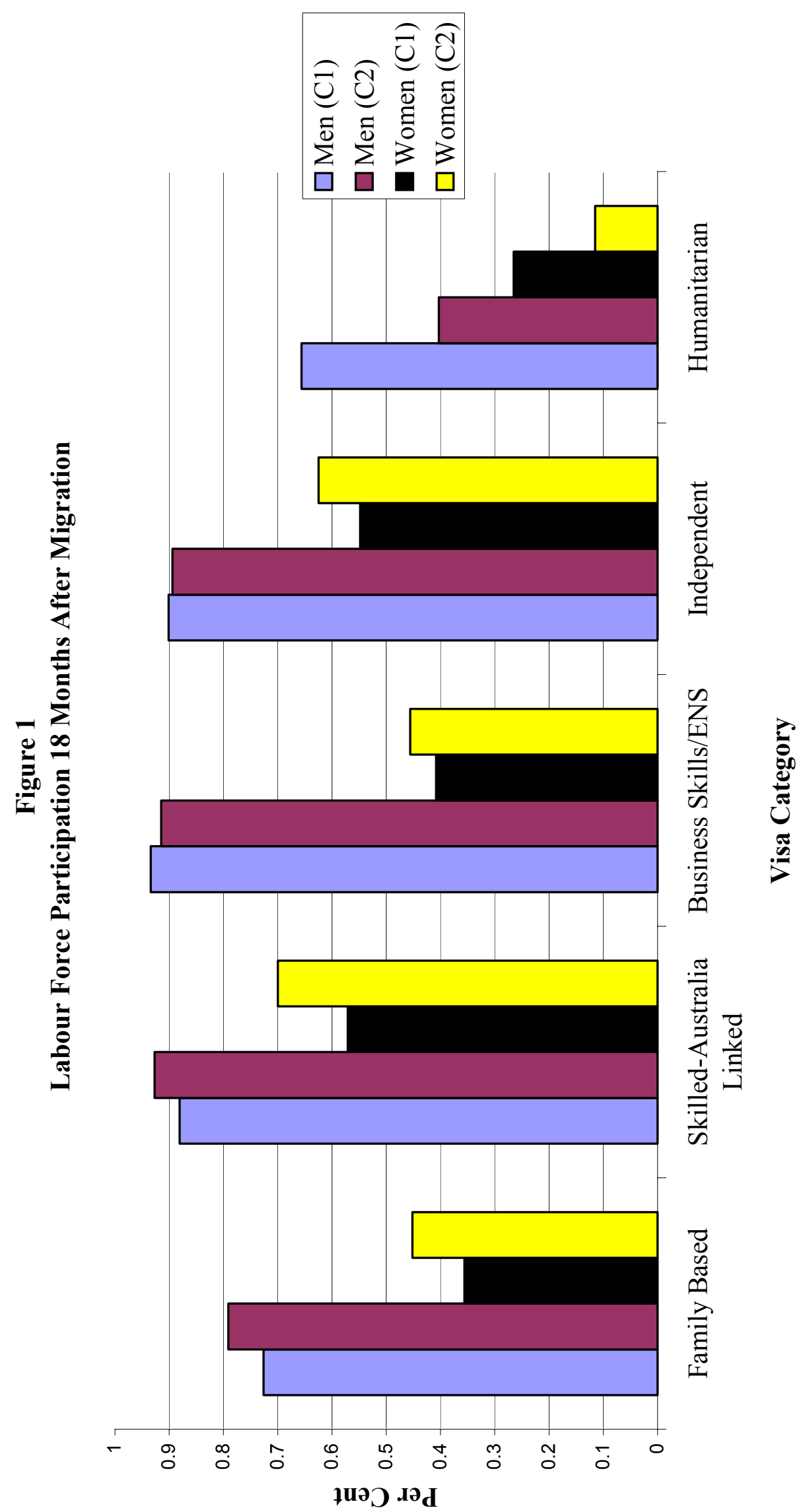




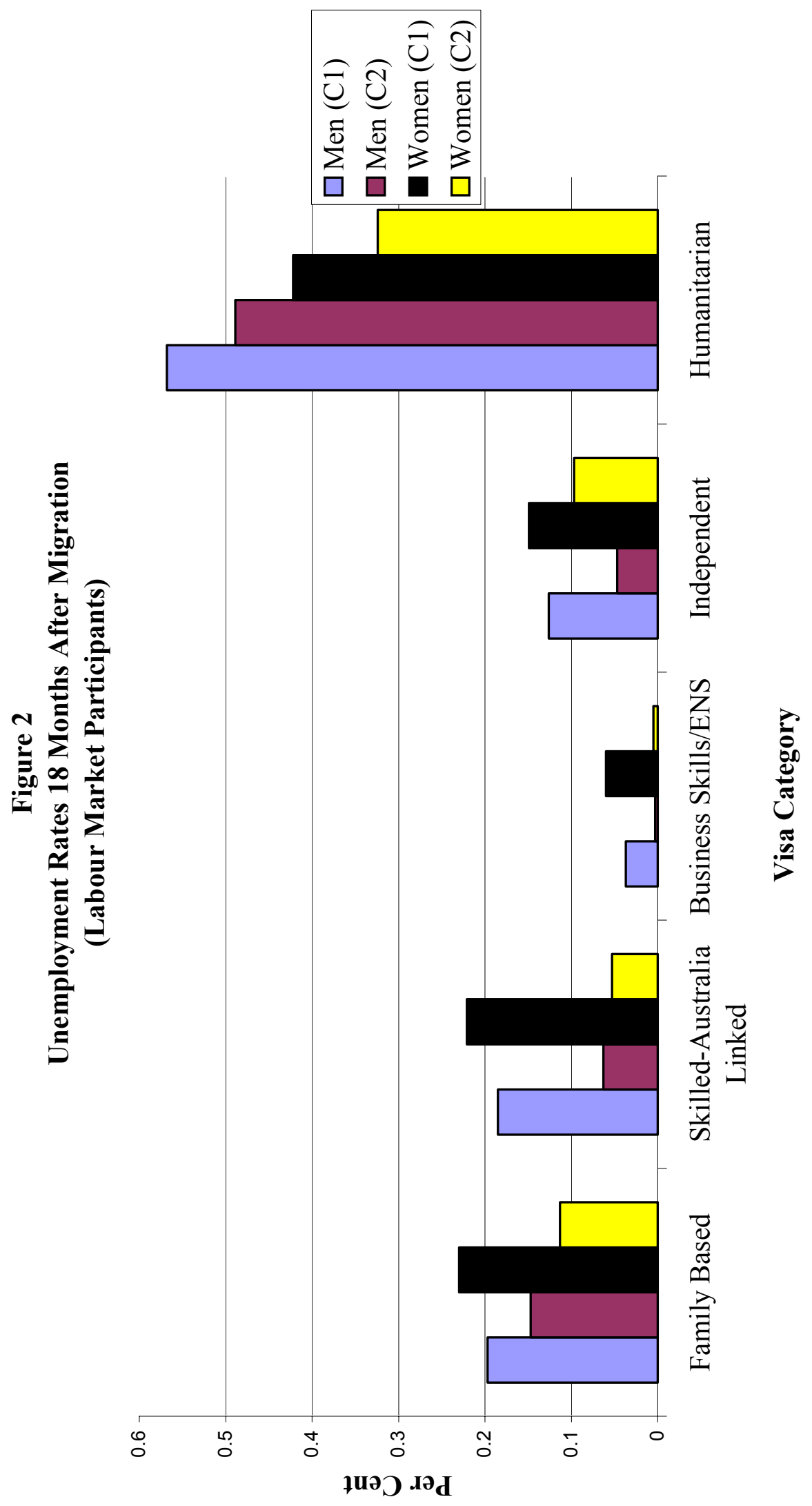




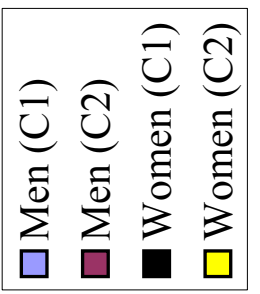

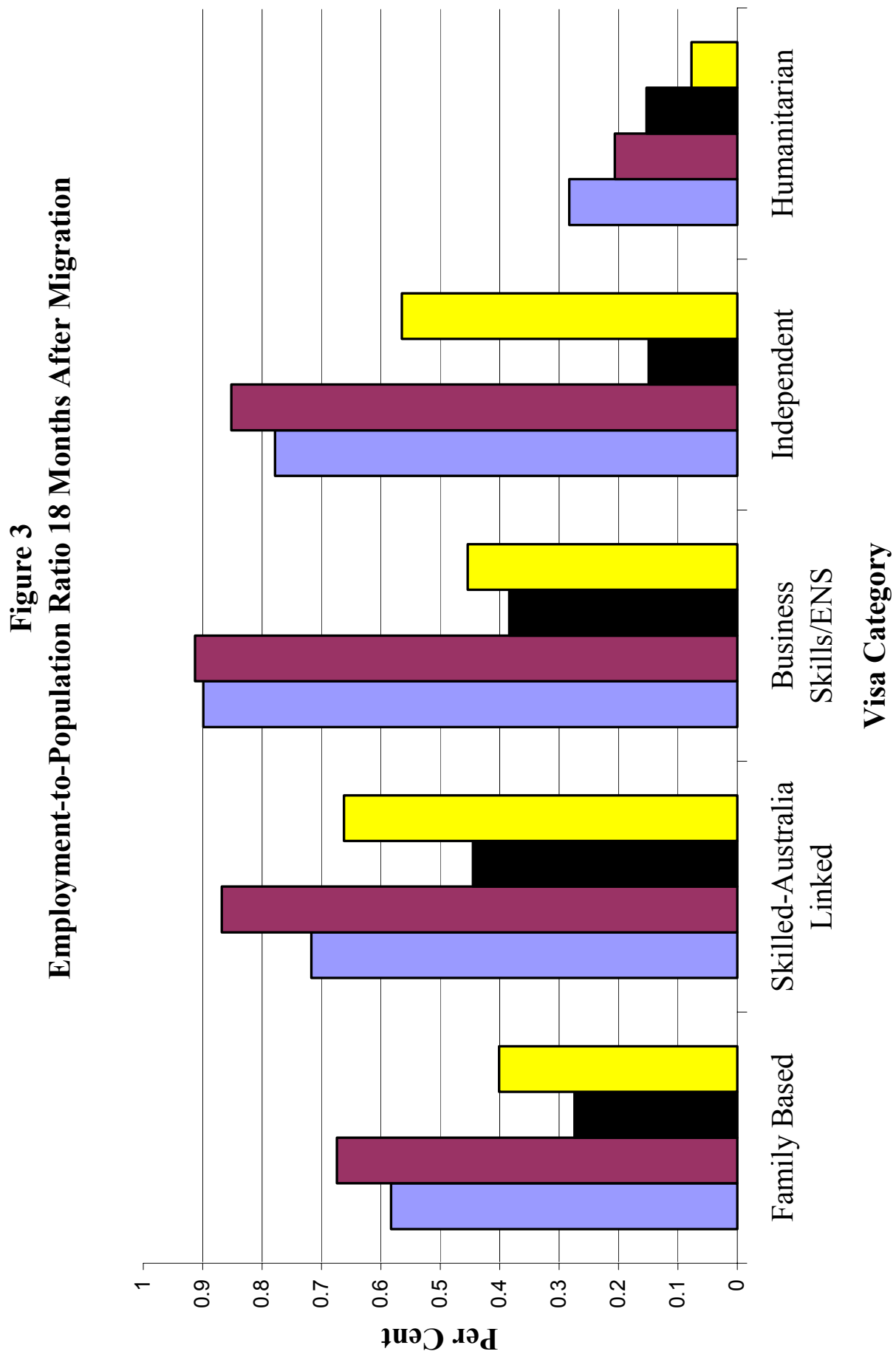




\section{APPENDIX}

To demonstrate the decomposition procedure let us first consider labour market participation. $^{24}$ Let the probability of immigrant $i$ being a labour market participant 18 months after immigration be given by:

$$
\operatorname{Pr}\left(P_{i j}=1\right)=\operatorname{Pr}\left(X_{i j} \beta_{j}+\varepsilon_{i j}>0\right)=\Phi\left(X_{i j} \beta_{j}\right)
$$

where $j=1,2$ indexes cohorts, $P_{i j}=1$ for labour market participants and 0 otherwise, $\varepsilon_{i j t} \sim N(0,1), \Phi$ is the standard normal cumulative distribution function, $\beta_{j}$ is a vector of parameters to be estimated separately for each cohort, while $X_{i j t}$ is a vector of demographic and human capital characteristics.

Let $\hat{X}_{j}$ capture the characteristics of a representative person of cohort $j$ at wave 2 approximately 18 months after migration. ${ }^{25}$ The predicted cohort gap in the probability of participating in the Australian labour market is given by:

$$
\hat{p}_{2}-\hat{p}_{1}=\Phi\left(\hat{X}_{2} \hat{\beta}_{2}\right)-\Phi\left(\hat{X}_{1} \hat{\beta}_{1}\right)
$$

Due to the non-linearity of the cumulative normal distribution, the cohort gap in the probability of participation is a non-linear function of $\hat{X}_{j}$ and $\hat{\beta}_{j}$ making standard decompositions impossible. To avoid this Doiron and Riddell (1994) suggest using a linear approximation. Specifically,

$$
\hat{p}_{2}-\hat{p}_{1}=\Phi\left(\hat{X}_{2} \hat{\beta}_{2}\right)-\Phi\left(\hat{X}_{1} \hat{\beta}_{1}\right) \cong \frac{\partial \Phi(\psi)}{\partial \psi}\left(\hat{X}_{2} \hat{\beta}_{2}-\hat{X}_{1} \hat{\beta}_{1}\right)
$$

\footnotetext{
${ }^{24}$ The decomposition procedure for the unemployment and employment-to-population rate is analogous.

25 The curvature of the normal distribution implies that using the sample means $\bar{X}_{j}$ to characterize the representative person results in predicted probabilities of participation that do not equal the sample averages. Furthermore, the problem differs by LSIA cohort, leading the participation gap between Cohort 1 and Cohort 2, for example, to be overstated for men and understated for women. Following, Doiron and Riddell (1994), a representative foreign-born individual $\left(\hat{X}_{j}\right)$ is defined such that he (she) has a predicted probability of, in this case, labour market participation equal to the cohort sample average and such that his (her) endowments are in the same proportion as the average endowments of foreign-born men (women) in the cohort. In effect, $\hat{X}_{j}=a_{j} \bar{X}_{j}$ where $a_{j}$ is a cohort-specific scaling factor.
} 
where $\psi=\left(N_{2} \hat{X}_{2} \hat{\beta}_{2}+N_{1} \hat{X}_{1} \hat{\beta}_{1}\right) /\left(N_{2}+N_{1}\right)$ is simply the predicted probability of participation for the representative members of Cohort 1 and Cohort 2 weighted by the respective sample sizes $N_{1}$ and $N_{2} \cdot{ }^{26}$ By adding and subtracting $\frac{\partial \Phi(\psi)}{\partial \psi} \hat{X}_{2} \hat{\beta}_{1}$ from the right hand side of equation (5) we can decompose the participation gap into returns- and characteristics-related components in the following manner:

$$
\hat{p}_{2}-\hat{p}_{1} \cong \frac{\partial \Phi(\psi)}{\partial \psi}\left[\hat{X}_{2}\left(\hat{\beta}_{2}-\hat{\beta}_{1}\right)+\hat{\beta}_{1}\left(\hat{X}_{2}-\hat{X}_{1}\right)\right]
$$

The decomposition given by equation (6) is obviously not unique. To assess the robustness of the results, two decompositions of the promotion gap are considered: the one given by equation (6) - $\mathrm{D}^{1}$ (which weights differences in characteristics by Cohort 1 returns)-and $\mathrm{D}^{2}$ (which weights differences in characteristics by Cohort 2 returns) and results from adding and subtracting $\frac{\partial \Phi(\psi)}{\partial \psi}\left(\hat{X}_{1} \hat{\beta}_{2}\right)$ in (5).

The above procedure was also used to decompose the unemployment rate and the employment-to-population ratio into characteristics- and returns-related components. These results are presented in Table 6.

\footnotetext{
${ }^{26}$ The first term on the right hand side is the standard normal probability density function evaluated at $\psi$.
} 